\title{
Article \\ Push-Out Tests on Various Steel Anchors with Partial-Length Welding in Steel-Concrete Composite Members
}

\author{
In-Rak Choi ${ }^{1}(1)$ and Chang-Soo Kim ${ }^{2, *}$ \\ 1 Department of Architecture and Civil Engineering, Hoseo University, 20, Hoseo-ro 79 beon-gil, Baebang-eup, \\ Asan-si, Chungcheongnam-do 31499, Korea; irchoi@hoseo.edu \\ 2 School of Architecture, Seoul National University of Science and Technology, 232 Gongreung-ro, Nowon-gu, \\ Seoul 01811, Korea \\ * Correspondence: changsookim@seoultech.ac.kr; Tel.: +82-2-970-6561
}

check for

updates

Citation: Choi, I.-R.; Kim, C.-S. PushOut Tests on Various Steel Anchors with Partial-Length Welding in SteelConcrete Composite Members. Appl. Sci. 2021, 11, 105. https://dx.doi.org/ 10.3390/app11010105

Received: 27 November 2020 Accepted: 20 December 2020 Published: 24 December 2020

Publisher's Note: MDPI stays neutral with regard to jurisdictional claims in published maps and institutional affiliations.

Copyright: () 2020 by the authors. Licensee MDPI, Basel, Switzerland. This article is an open access article distributed under the terms and conditions of the Creative Commons Attribution (CC BY) license (https: / / creativecommons.org/ licenses/by/4.0/).

\section{Featured Application: Steel-Concrete Composite Structures.}

\begin{abstract}
To investigate the behavior of various steel anchors, push-out tests were performed for 13 test specimens. Test parameters included the geometry of beams (wide-flange beams and composite beams) and the type of steel anchors (stud anchors and Z- and C-channel anchors with full- or partial-length welding). Test results showed that the performance of test specimens strongly depends on the types of steel anchors rather than the geometry of steel beams. The specimens with C-channel anchors showed the highest load-carrying capacity but the most drastic load reduction after the peak load. The specimens with Z-channel anchors showed a similar behavior to those with C-channel anchors but the load reduction occurred at a slightly slower rate. The load-carrying capacity was increased with the length of the Z- and C-channel anchors. The specimens with stud anchors reached the peak load at a slow rate and showed the most ductile behavior. The test results were compared with predictions by various design equations for steel anchors available in the literature, and the existing design equations for channel anchors with partial-length welding were considered applicable to design.
\end{abstract}

Keywords: composite structure; steel anchor; channel anchor; partial-welding; push-out test

\section{Introduction}

Steel-concrete composite members show high load-carrying capacity, high local stability, and high stiffness due to the composite action of steel and concrete $[1,2]$. To achieve the desired composite action or to transfer longitudinal shear between steel and concrete, steel anchors or shear connectors should be provided at the interface between the steel and concrete [1,3]. For this purpose, steel-headed stud anchors (hereafter, stud anchors) have been most widely used, but recently steel shape anchors such as C-, L-, T- and Z-channels (hereafter, channel anchors collectively) have also gained popularity since conventional welding equipment can be used and the required performance can be obtained with a smaller number of connectors [3,4].

In general, channel anchors are welded to the base steel sections along the full length of the anchors. However, in some cases of composite members using U-shaped or built-up sections [4-6], only both ends of the channel anchors are welded to base steel sections. In those cases, the partially welded channel anchors can function as (1) steel anchors as intended, (2) battens to form a closed or built-up section, and (3) walk-plates or steps during construction. Figure 1 shows an example that utilizes partially welded Z-channel anchors to a composite beam: an H-beam (or wide-flange beam) with a concrete-filled U-shaped flange (hereafter, UH-beam). As shown in the figure, the partially welded channel anchors can be used as an alternative to the combined conventional stud anchors and battens. 


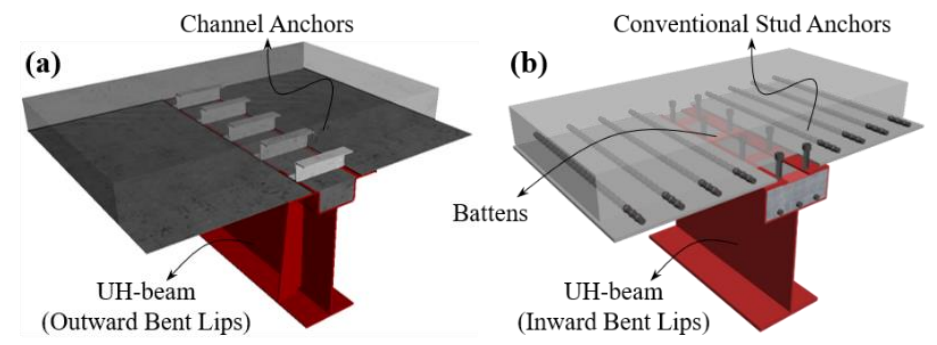

Figure 1. Application of steel anchors to UH-beams: (a) UH-beam with Z-channel anchors; (b) UHbeam with conventional stud anchors.

For the performance and design of channel anchors, numerous studies have been conducted. Viest et al. [7] carried out tests for push-out and beam specimens (consisting of steel beams and concrete slabs) using C-channel anchors and found that the strength of the concrete and the web thickness, flange thickness, and length of the channel anchor affected the load-carrying capacity of the test specimens, but the height and orientation of the channel anchor had negligible effects. They provided a theoretical analysis model, assuming that the channel anchor acts as a dowel. Slutter and Driscoll [8] also carried out push-out and beam tests, and proposed a design equation for the strength of C-channel anchors. The design equation of Slutter and Driscoll [8] is adopted in ANSI/AISC 360-16 [9] and KDS 413100 [10] with a modification, and CSA S16-09 [11] also specifies a similar form of design equation. It is noteworthy that slip between the steel beam and concrete slab is inevitable [7], but the slip is not an important factor of the ultimate load of test specimens if a sufficient number of steel anchors are provided [8]. Yokota and Kiyomiya [12] carried out push-out tests using L-, C-, and T-channel anchors and found that the test specimens failed by the tensile fracture of steel anchors, crushing of concrete, or shear failure of concrete, and the failure modes were affected by the shape and direction of the steel anchors and the strength of concrete. Maleki and Mahoutian [13] performed experimental and analytical studies for C-channel anchors embedded in unconfined (without stirrups) normal or polypropylene concrete slabs and found that the specimens without stirrups failed in a more brittle way and show much lower strength than a specimen with stirrups. Pashan and Hosain [14] carried out push-out tests with test parameters of the concrete strength and the length and web thickness of C-channel anchors, and suggested a design equation, which was simplified from their previous study. Ros [15] developed a type of sandwich beam test method and proposed equations for the design of L-channel anchors as a function of strut angle and also for the shear force-relative displacement relationship. Baran and Topkaya [3] formulated a design equation for C-channel anchors based on the typical failure mechanism in push-out tests and plastic analysis principles. Tahmasbi et al. [16] performed finite element simulations for L- and inversed L-channel anchors (where "inversed" indicates that the angle is in a sitting position or has no top flange) embedded in a concrete slab, and suggested a design equation based on the parametric study results. JSCE [17] provides design equations for stud anchors and L-channel anchors, and Qiu et al. [18] modified the JSCE's design equation for the design of L- and T-channel anchors based on their push-out test results with unreinforced concrete slabs (to simulate composite sandwich structures). It is noted that the current version of Eurocode 4-04 [19] provides a design equation only for stud anchors.

Each of these previous studies provides a valuable insight into the design of steel anchors but the majority of the previous studies, including the current design codes, are for channel anchors with full-length welding. Considering the fact that steel anchors with partial-length welding are also widely used in practice with the increasing application of U-shaped or built-up sections, more experimental studies are required for partially welded channel anchors, and the applicability of design equations to the partially welded channel anchors needs to be examined. 
In the present study, to investigate the behavior of various steel anchors, push-out tests were performed for 13 test specimens. Test parameters included the geometry of steel beams (H-beams and UH-beams) and the type of steel anchors (stud anchors, and Zand C-channel anchors with full- or partial-length welding). Test results were compared with predictions by existing design equations for steel anchors, and the applicability of the equations to the partially welded channel anchors was discussed.

\section{Test Program}

\subsection{Test Specimens}

Figure 2 shows the push-out test specimens. A total of 13 specimens were prepared, and the test parameters included the geometry of the steel beams and the type of steel anchors. Table 1 summarizes the test parameters. The configuration and dimensions of the test specimens were determined in accordance with the standard test of shear connectors specified in Eurocode 4-04 [19], but some dimensions were minorly adjusted to accommodate the details of the test parameters: the test specimens were $600 \times 600 \mathrm{~mm}$ in section and $700 \mathrm{~mm}$ in height.

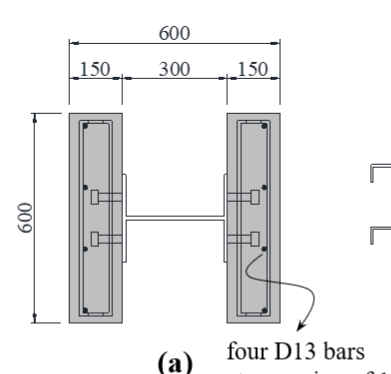

(a) at a spacing of $175 \mathrm{~mm}$

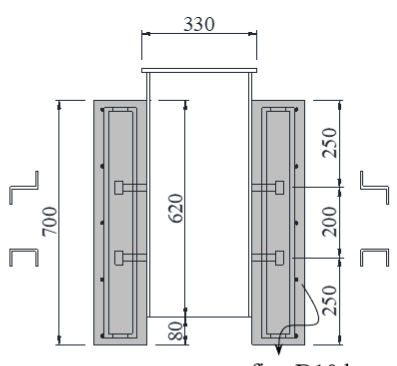

(b) five D10 bars
at a spacing of $160 \mathrm{~mm}$

(c)

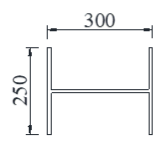

H-beams

\begin{tabular}{|l|}
\hline \multicolumn{2}{|c|}{ Stud Anchors } \\
\hline$\phi 19$
\end{tabular}

Z-channel Anchors

$$
\text { की }
$$

C-channel Anchors

$t=6$

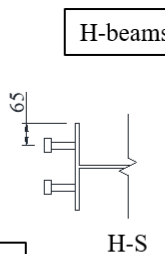

H-S

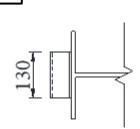

H-Z130

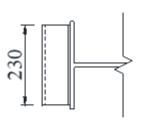

H-Z230
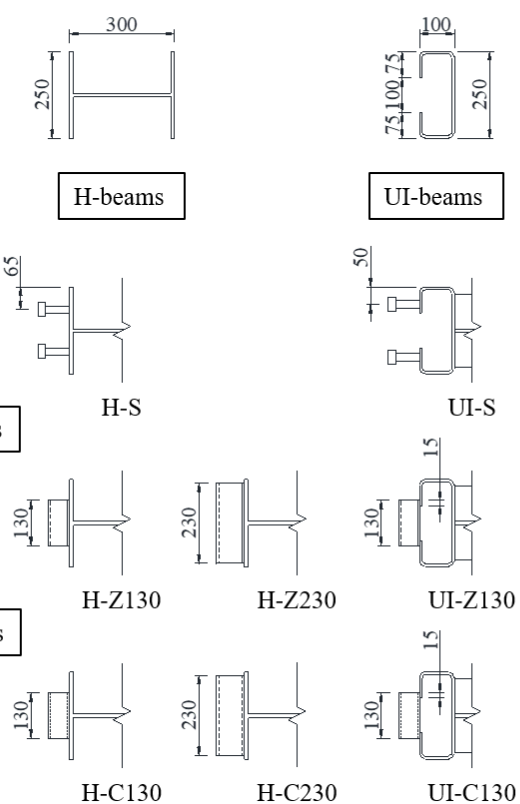

UI-S

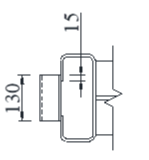

UI-Z130
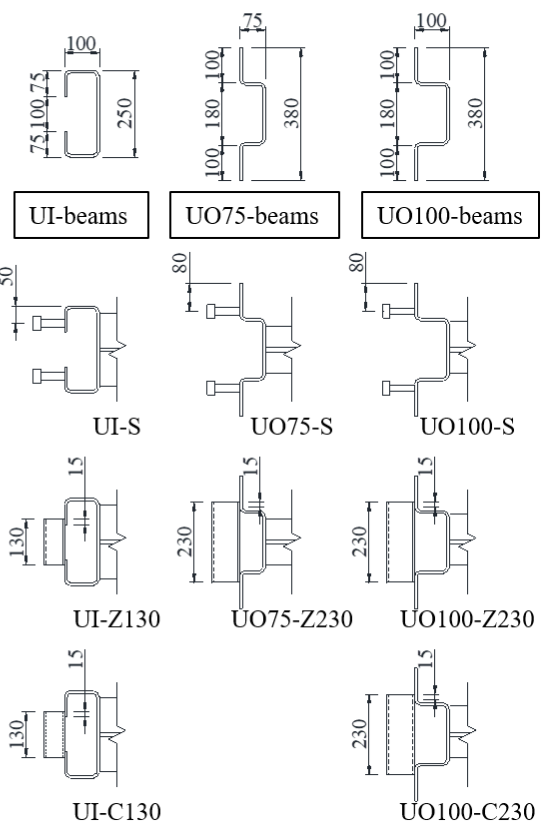

Figure 2. Test specimens (units in $\mathrm{mm}$ ): (a) typical section; (b) typical elevation; (c) details of the steel beam and steel anchor. 
Table 1. Test parameters.

\begin{tabular}{|c|c|c|c|c|}
\hline Group & Specimen ${ }^{1}$ & Steel Beam ${ }^{2}$ & $\begin{array}{l}\text { Steel Anchors }{ }^{2} \\
\text { (Length) }\end{array}$ & Concrete Slabs \\
\hline \multirow[t]{4}{*}{$\mathrm{S}$} & HS & $\mathrm{H}-300 \times 250 \times 10 \times 10 \mathrm{~mm}$ & $\mathrm{~S}-\phi 19 \times 90 \mathrm{~mm}$ & $150 \times 600 \mathrm{~mm}$ \\
\hline & UI-S & $\mathrm{UI}-100 \times 250 \times 8 \times 75 \mathrm{~mm}$ & $\mathrm{~S}-\phi 19 \times 90 \mathrm{~mm}$ & \\
\hline & UO75-S & $\mathrm{UO}-75 \times 180 \times 8 \times 100 \mathrm{~mm}$ & $\mathrm{~S}-\phi 19 \times 90 \mathrm{~mm}$ & \\
\hline & UO100-S & $\mathrm{UO}-100 \times 180 \times 8 \times 100 \mathrm{~mm}$ & $\mathrm{~S}-\phi 19 \times 90 \mathrm{~mm}$ & \\
\hline \multirow[t]{5}{*}{$\mathrm{Z}$} & H-Z130 & $\mathrm{H}-300 \times 250 \times 10 \times 10 \mathrm{~mm}$ & $\mathrm{Z}-80 \times 50 \times 6 \times 6 \mathrm{~mm}(130 \mathrm{~mm})$ & \\
\hline & H-Z230 & $\mathrm{H}-300 \times 250 \times 10 \times 10 \mathrm{~mm}$ & $\mathrm{Z}-80 \times 50 \times 6 \times 6 \mathrm{~mm}(130 \mathrm{~mm})$ & \\
\hline & UI-Z130 & $\mathrm{UI}-100 \times 250 \times 8 \times 75 \mathrm{~mm}$ & $\mathrm{Z}-80 \times 50 \times 6 \times 6 \mathrm{~mm}(130 \mathrm{~mm})$ & \\
\hline & UO75-Z230 & $\mathrm{UO}-75 \times 180 \times 8 \times 100 \mathrm{~mm}$ & $\mathrm{Z}-80 \times 50 \times 6 \times 6 \mathrm{~mm}(130 \mathrm{~mm})$ & \\
\hline & UO100-Z230 & $\mathrm{UO}-100 \times 180 \times 8 \times 100 \mathrm{~mm}$ & $\mathrm{Z}-80 \times 50 \times 6 \times 6 \mathrm{~mm}(130 \mathrm{~mm})$ & \\
\hline \multirow[t]{4}{*}{$\mathrm{C}$} & $\mathrm{H}-\mathrm{C} 130$ & $\mathrm{H}-300 \times 250 \times 10 \times 10 \mathrm{~mm}$ & $\mathrm{C}-80 \times 50 \times 6 \times 6 \mathrm{~mm}(130 \mathrm{~mm})$ & \\
\hline & $\mathrm{H}-\mathrm{C} 230$ & $\mathrm{H}-300 \times 250 \times 10 \times 10 \mathrm{~mm}$ & $\mathrm{C}-80 \times 50 \times 6 \times 6 \mathrm{~mm}(130 \mathrm{~mm})$ & \\
\hline & UI-C130 & $\mathrm{UI}-100 \times 250 \times 8 \times 75 \mathrm{~mm}$ & $\mathrm{C}-80 \times 50 \times 6 \times 6 \mathrm{~mm}(130 \mathrm{~mm})$ & \\
\hline & UO100-C230 & $\mathrm{UO}-100 \times 180 \times 8 \times 100 \mathrm{~mm}$ & $\mathrm{C}-80 \times 50 \times 6 \times 6 \mathrm{~mm}(130 \mathrm{~mm})$ & \\
\hline
\end{tabular}

\footnotetext{
${ }^{1}$ Designation: geometry of steel beam—type of steel anchor; ${ }^{2}$ Dimensions of steel shapes: wide-flange section: H—height $\times$ width $\times$ web thickness $\times$ flange thickness; U-channel with inward/outward bent lips: UI/UO-height $\times$ bottom width $\times$ thickness $\times$ top lip width; headed stud anchor: S- $\phi$ shank diameter $\times$ length; Z-channel anchor: Z-height $\times$ flange width $\times$ web thickness $\times$ flange thickness; and C-channel anchor: $\mathrm{C}$-height $\times$ width $\times$ web thickness $\times$ flange thickness.
}

Steel beams varied in geometry, namely conventional H-beams and UH-beams. For the H-beams, welded built-up wide-flange sections of $300 \times 250 \times 10 \times 10 \mathrm{~mm}(\mathrm{H}$-height $\times$ width $\times$ web thickness $\times$ flange thickness) were used. On the other hand, for the U-shaped flange of the UH-beams, lip channels (or U-channels with inward bent lips: UI) of $100 \times 250 \times 8 \times 75 \mathrm{~mm}$ and hat channels (or U-channels with outward bent lips: UO) of $100 \times 180 \times 8 \times 100 \mathrm{~mm}$ or $75 \times 180 \times 8 \times 100 \mathrm{~mm}$ (UI/UO-height $\times$ bottom width $\times$ thickness $\times$ top lip width) were used. Two symmetric U-shaped flanges were connected by a 10-mm-thick web plate for double-sided push-out testing, and all steel beams were identical in total section height.

For steel anchors, stud anchors of $2-\phi 19 \times 90 \mathrm{~mm}$ (two rows of S- $\phi$ shank diameter $\times$ length), Z-channels of $80 \times 50 \times 6 \times 6 \mathrm{~mm}$ (Z-height $\times$ flange width $\times$ web thickness $\times$ flange thickness), and C-channels of $80 \times 50 \times 6 \times 6 \mathrm{~mm}(\mathrm{C}$ - height $\times$ width $\times$ web thickness $\times$ flange thickness) were used. The $\mathrm{Z}$ - and C-channel anchors varied in length $(130 \mathrm{~mm}$ and $230 \mathrm{~mm}$ ) to accommodate the spacing between the two top lips bent inward or outward, and all steel anchors were spaced at $200 \mathrm{~mm}$ and placed symmetrically in both concrete slabs. The welded length of all channel anchors used in UH-beams was $15 \mathrm{~mm}$ measured at one end, while in $\mathrm{H}$-beams, channel anchors were welded to the beam flange along the full length of the anchors.

Two symmetric concrete slabs of $150 \mathrm{~mm}$ thickness were connected to the flanges of a steel beam through steel anchors. Each of the concrete slabs was cast in the horizontal position, and greasing was provided on the flanges of the steel beam to prevent bonding at the interface between the flanges and concrete slabs [19]. For reinforcement, vertical bars of D13 (nominal diameter $=12.7 \mathrm{~mm}$ [20]) were placed at a spacing of $175 \mathrm{~mm}$ and horizontal bars of D10 (nominal diameter $=9.53 \mathrm{~mm}$ [20]) were placed at a spacing of $160 \mathrm{~mm}$.

In each test specimen, test parameters (geometry of steel beams and type of steel anchor) were combined and each test specimen was referred to by a designation which includes these two test parameters: in the designation, the numerals after UO refer to the depth of the concrete-filled U-shaped flange, and the numerals after $\mathrm{Z}$ and $\mathrm{C}$ refer to the length of the Z- and C-channel anchors.

\subsection{Material Properties}

For steel beams and Z- and C-channel anchors, SM355 steel plates were used (specified minimum yield stress $=355 \mathrm{MPa}$ and specified minimum tensile strength $=490 \mathrm{MPa}$ [10]), while for stud anchors, HS1 studs were used (specified minimum yield stress $=235 \mathrm{MPa}$ 
and specified minimum tensile strength $=400 \mathrm{MPa}$ [21]). For concrete, C24 was used (specified compressive strength $=24 \mathrm{MPa}$ ).

For steel coupons sampled from the steel beams and steel anchors, tension tests were carried out according to KS B 0802 [22]. Before the tension tests, actual dimensions such as the thickness of plates and the shank diameter of studs were also measured. For each concrete mix, four concrete cylinders were prepared and cured alongside the test specimens [19]. On the day of testing, compression tests were carried out for the concrete cylinders according to KS F 2405 [23].

The measured material properties such as the mean yield strength and tensile strength of steel and the mean compressive strength $\left(f^{\prime}{ }_{c}\right)$ of concrete are summarized in Table 2. It is noted that since the last four specimens (No. 10-13 in Table 1) were additionally tested after testing the first nine specimens (No. 1-9 in Table 1), SM355-10T, SM355-8T, SM355-6T, and C24 had two different material properties.

Table 2. Measured material properties.

\begin{tabular}{|c|c|c|c|c|c|c|}
\hline $\begin{array}{l}\text { Structural } \\
\text { Component }\end{array}$ & Material $^{1}$ & $\begin{array}{l}\text { Thickness } \\
\text { (mm) }\end{array}$ & $\begin{array}{c}\text { Yield } \\
\text { Strength } \\
\text { (MPa) }\end{array}$ & $\begin{array}{c}\text { Ultimate } \\
\text { Strength } \\
\text { (MPa) }\end{array}$ & $\begin{array}{l}\text { Elongation } \\
\text { (\%) }\end{array}$ & Remarks \\
\hline \multirow{4}{*}{ Steel Beam } & SM355-10T & 10.1 & 404.7 & 551.9 & 23.6 & No. $1-9$ \\
\hline & (H-beam and web of UH-beam) & 10.0 & 385.0 & 522.7 & 24.7 & No. $10-13$ \\
\hline & SM355-8T & 8.1 & 446.3 & 541.5 & 23.0 & No. $1-9$ \\
\hline & (flange of UH-beam) & 7.8 & 304.7 & 473.0 & 27.3 & No. $10-13$ \\
\hline \multirow{2}{*}{ Steel Anchors } & $\begin{array}{c}\text { HS1- } \phi 19 \\
\text { (stud anchor) }\end{array}$ & 19.0 & 413.8 & 478.7 & 17.3 & \\
\hline & $\begin{array}{c}\text { SM355-6T } \\
\text { (Z-channel anchor) }\end{array}$ & 6.0 & 406.8 & 524.4 & 32.7 & \\
\hline & $\begin{array}{c}\text { SM355-6T } \\
\text { (C-channel anchor) }\end{array}$ & 5.8 & 533.3 & 606.3 & 18.7 & \\
\hline Slab & $\begin{array}{c}\text { C24 } \\
\text { (Concrete) }\end{array}$ & \multicolumn{5}{|c|}{$\begin{array}{c}\left.f^{\prime}{ }_{c}=28.0 \mathrm{MPa} \text { at the day of testing (No. } 1-9\right) \\
f^{\prime}{ }_{c}=30.3 \mathrm{MPa} \text { at the day of testing (No. } 10-13 \text { ) }\end{array}$} \\
\hline
\end{tabular}

${ }^{1}$ Since the C-group was additionally tested after testing the S- and Z-groups, SM355-10T, SM355-8T, SM355-6T, and C24 had two different material properties.

\subsection{Test Setup and Instrumentation}

Figure 3 shows the test setup for push-out testing. Considering the longitudinal slip between the concrete slabs and steel beam, the steel beam protruded $80 \mathrm{~mm}$ from the top of concrete slabs. A loading plate $(\mathrm{PL}-330 \times 380 \times 10)$ was provided on the top of the steel beam, and through a $10 \mathrm{MN}$ universal testing machine (UTM), monotonic loading was applied to the loading plate under displacement control $(1.8 \mathrm{~mm} / \mathrm{min})$. To prevent eccentric loading, test specimens were carefully aligned to the center of loading and the testing was terminated when the load dropped to $80 \%$ of the peak load [24].

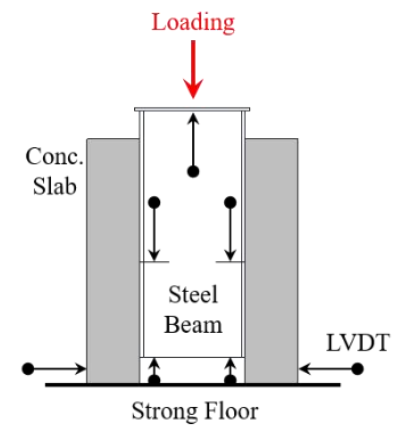

Figure 3. Test setup.

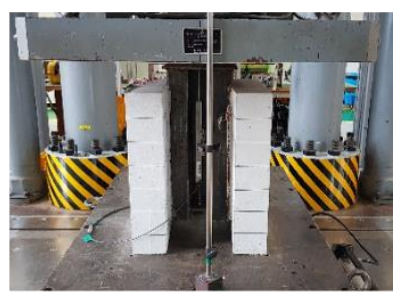


To measure displacement, 7 linear variable displacement transducers (LVDTs) were installed around the test specimen: one beneath the loading plate, two under the steel beam, two on the inner surfaces of the concrete slabs, and two for transverse separation of the concrete slabs from the steel beam. To measure strain, strain gauges were also placed on steel anchors.

\section{Test Results}

\subsection{Failure Modes}

Figure 4 shows the test specimens at the end of push-out testing. The overall behavior and failure mode varied with the type of steel anchor.
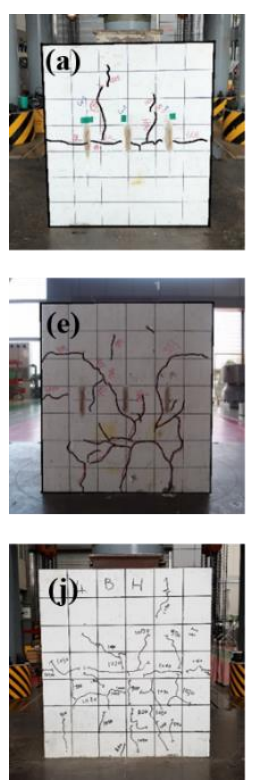
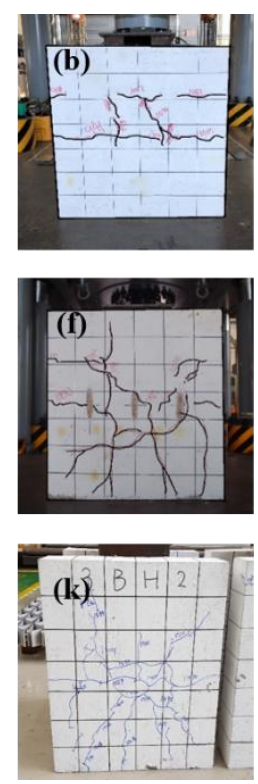
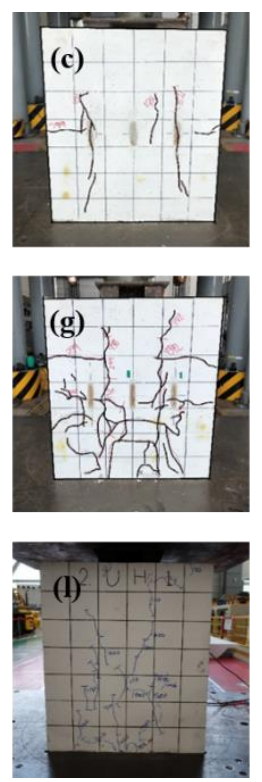
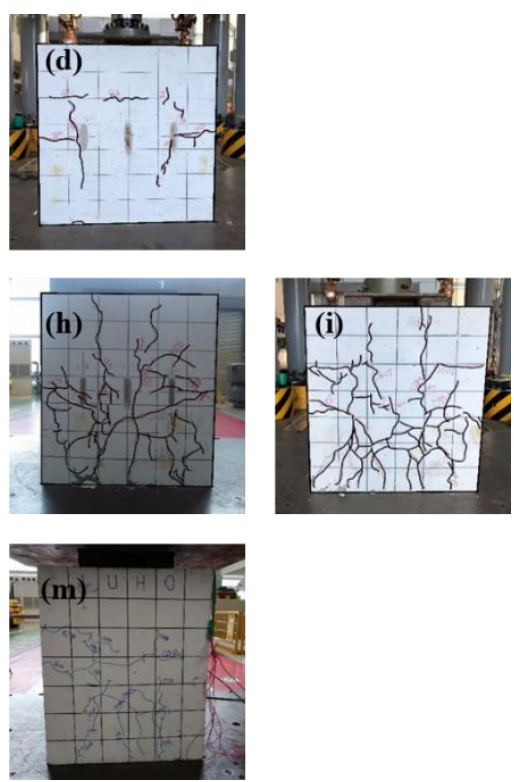

Figure 4. Failure Modes: (a) H-S; (b) UI-S; (c) UO75-S; (d) UO100-S; (e) H-Z130; (f) H-Z230; (g) UIZ130; (h) UO75-Z230; (i) UO100-Z230; (j) H-C130; (k) H-C230; (l) UI-C130; (m) UO100-C230.

In the case of the S-group (H-S, UI-S, UO75-S, and UO100-S using stud anchors; Figure $4 \mathrm{a}-\mathrm{d})$, the test specimens failed by fracture of the studs at the bottom of the studs. Crushing and cracking of concrete occurred first around the root of studs. The bottom and sides of the concrete slabs also showed crushing and minor longitudinal cracking. Under further loading, splitting of concrete occurred on the exterior surfaces of the concrete slabs (but the splitting was limited) and the load increment was gradually decreased. The peak load was reached by fracture of the studs, and then the load was suddenly dropped and concrete slabs were separated (about 1-2 mm) from the steel beam.

In the case of the Z-group (H-Z130, H-Z230, UI-Z130, UO75-Z230, and UO100-Z230 using Z-channel anchors; Figure 4e-i), the test specimens failed by splitting of the concrete. The splitting of concrete was initiated at the locations of the steel anchors and propagated to the outside. Compared with the S-group, the peak load was reached earlier, and the splitting on the exterior surfaces of concrete slabs and the crushing of concrete around the interface between the steel beam and concrete slabs were more prominent. However, the degradation in load after the peak was less drastic. The test specimens of C-group (H-C130, H-C230, UI-C130, and UO100-C230 using C-channel anchors: Figure 4j-m) were also failed by splitting of concrete as in Z-group. In Z- and C-groups, the separation of concrete slabs from the steel beam was about $6-15 \mathrm{~mm}$ after the test.

The failure mode was not clearly distinguished by the geometry of steel beams, but in the case of using the U-channel with outward bent lips (UO) for the steel beam, the longitudinal slip between the steel beam and concrete slabs was most prominent. 


\subsection{Shear Force-Slip Relationship}

Figure 5 shows the shear force-slip relationship. To quantify the effects of test parameters, the maximum strength, initial stiffness, and slip capacity were evaluated from the test results. The maximum strength $\left(V_{m}\right)$ was taken as the peak load. The initial stiffness $\left(K_{i}\right)$ was taken as the secant stiffness at the point where steel anchors reached the yield strain, and the yielding of steel anchors was determined by the measurement as shown in Figure 6 . The slip capacity $(\mu)$ was taken as the ratio of yield slip-to-ultimate slip $\left(\delta_{y} / \delta_{u}\right)$, in which the yield slip $\delta_{y}$ was defined as the slip measured at the yielding of steel anchors and the ultimate slip was defined as the slip corresponding to $0.8 V_{m}$ after the peak load [24]. The performance points of $\delta_{y}, V_{m}$, and $\delta_{u}$ are marked with a circle, triangle, and cross on each plot of Figure 5, respectively, and the test results are summarized in Table 3.
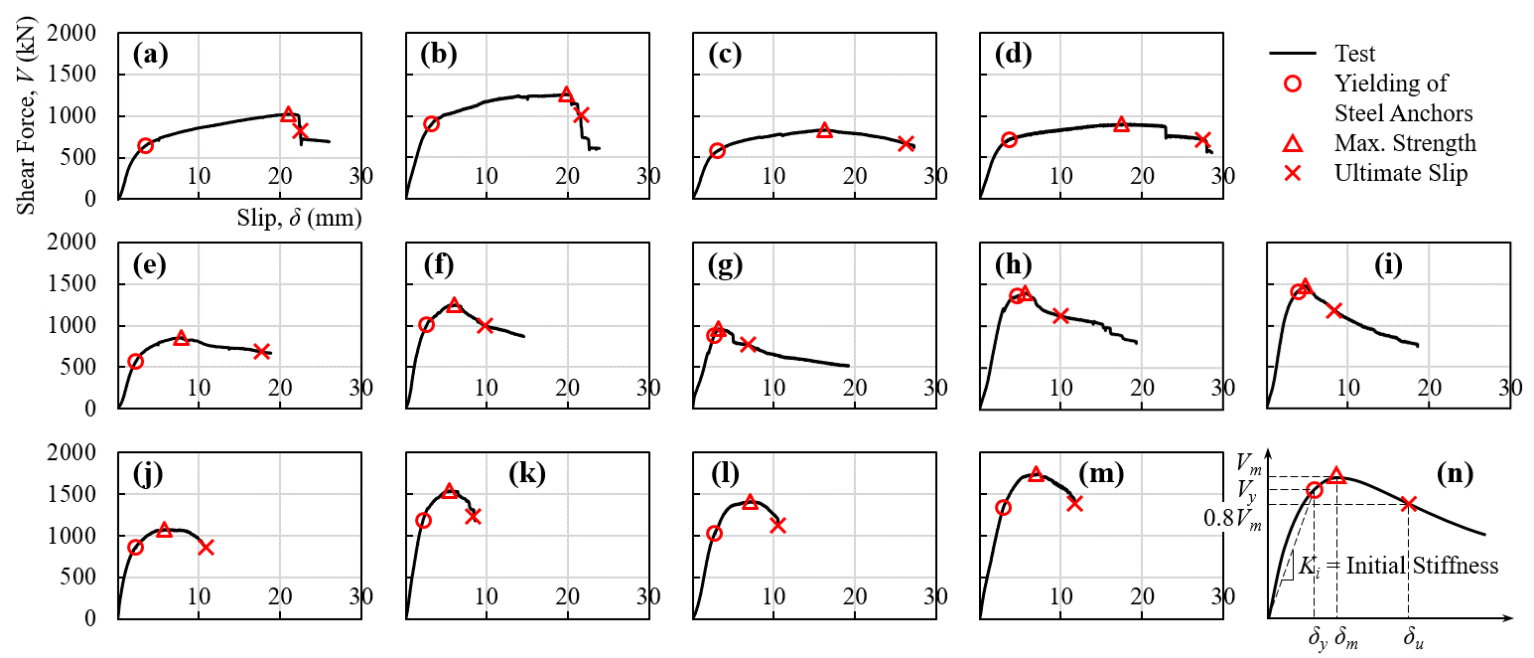

Figure 5. Shear Force-Slip Relationship: (a) H-S; (b) UI-S; (c) UO75-S; (d) UO100-S; (e) H-Z130; (f) H-Z230; (g) UI-Z130; (h) UO75-Z230; (i) UO100-Z230; (j) H-C130; (k) H-C230; (1) UI-C130; (m) UO100-C230; (n) Definitions of Performance Points.

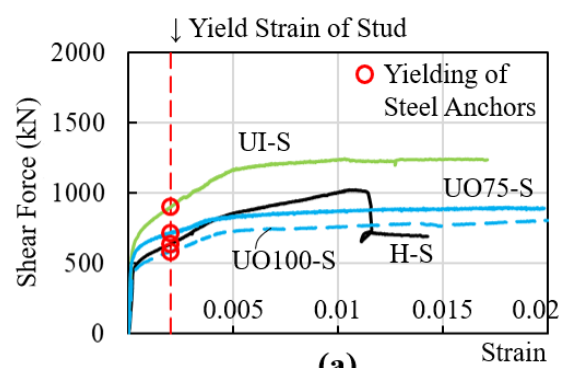

(a)

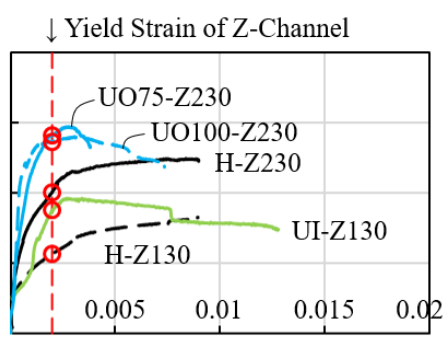

(b)

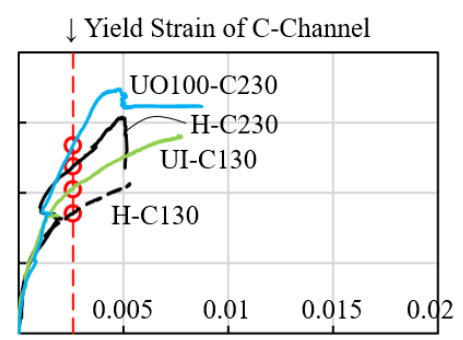

(c)

Figure 6. Shear Force-Strain Relationship of Steel Anchors: (a) S-group; (b) Z-group; (c) C-group.

To clarify the effect of each test parameter, the shear force-slip behavior was compared in terms of steel anchors in Figure 7a, and in terms of steel beams in Figure 7b.

The figure reconfirms the higher effect of steel anchors than steel beams on structural behavior: similar behavior in Figure 7a for same steel anchors with different steel beams; but large difference in behavior in Figure $7 \mathrm{~b}$ for same steel beams with different steel anchors. In general, the geometry of steel beams and the depth of the concrete-filled U-shaped flange (UO75 and UO100) had no significant effect. A similar observation can be found in a previous study [18]: for most shear connectors in push-out tests, the effect of the thickness of the connected plate could be ignored. On the other hand, the type of steel anchors had a distinct effect. The specimens with C-channel anchors showed highest load-carrying capacity, but the load reduction after the peak load was most drastic. The specimens with Z-channel anchors showed a similar behavior to those with C-channel 
anchors, but the load reduction occurred in a slightly slower rate. As the length of channel anchors increased (Z130 and Z230 or C130 and C230 with the same welded length), the loadcarrying capacity was increased. Although there was also a sudden drop after reaching the peak load even in the case of using stud anchors, the specimens with stud anchors reached the peak load in a slow rate and showed most ductile behavior.

Table 3. Test Results.

\begin{tabular}{|c|c|c|c|c|c|c|}
\hline \multirow[b]{2}{*}{ Specimen } & \multicolumn{3}{|c|}{ Yielding of Steel Anchors } & \multirow{2}{*}{$\begin{array}{c}\text { Maximum Strength } \\
V_{m} \\
(\mathbf{k N})\end{array}$} & \multicolumn{2}{|c|}{ Ultimate Slip } \\
\hline & $\begin{array}{c}V_{y} \\
(\mathbf{k N})\end{array}$ & $\begin{array}{c}\delta_{y} \\
(\mathrm{~mm})\end{array}$ & $\begin{array}{c}K_{i}=V_{y} / \delta_{y} \\
(\mathrm{kN} / \mathrm{mm})\end{array}$ & & $\begin{array}{c}\delta_{u} \\
(\mathrm{~mm})\end{array}$ & $\mu=\delta_{u} / \delta_{y}$ \\
\hline H-S & 640.0 & 3.4 & 190.9 & 1024.6 & 22.5 & 6.7 \\
\hline UI-S & 901.5 & 3.2 & 284.2 & 1262.5 & 21.6 & 6.8 \\
\hline UO75-S & 718.6 & 3.7 & 195.4 & 900.0 & 27.5 & 7.5 \\
\hline UO100-S & 584.0 & 3.1 & 189.7 & 834.1 & 26.3 & 8.5 \\
\hline H-Z130 & 566.3 & 2.2 & 260.3 & 861.2 & 17.8 & 8.2 \\
\hline $\mathrm{H}-\mathrm{Z} 230$ & 1008.3 & 2.6 & 389.9 & 1246.5 & 9.7 & 3.8 \\
\hline UI-Z130 & 876.8 & 2.6 & 335.1 & 963.5 & 6.9 & 2.6 \\
\hline UO75-Z230 & 1411.2 & 3.9 & 363.0 & 1473.3 & 8.4 & 2.1 \\
\hline UO100-Z230 & 1362.7 & 4.6 & 297.9 & 1401.2 & 10.0 & 2.2 \\
\hline $\mathrm{H}-\mathrm{C} 130$ & 857.7 & 2.2 & 392.4 & 1077.0 & 10.9 & 5.0 \\
\hline $\mathrm{H}-\mathrm{C} 230$ & 1191.0 & 2.2 & 553.9 & 1541.8 & 8.4 & 3.9 \\
\hline UI-C130 & 1025.3 & 2.7 & 384.0 & 1409.8 & 10.4 & 3.9 \\
\hline UO100-C230 & 1340.5 & 2.9 & 456.2 & 1740.9 & 11.7 & 4.0 \\
\hline
\end{tabular}
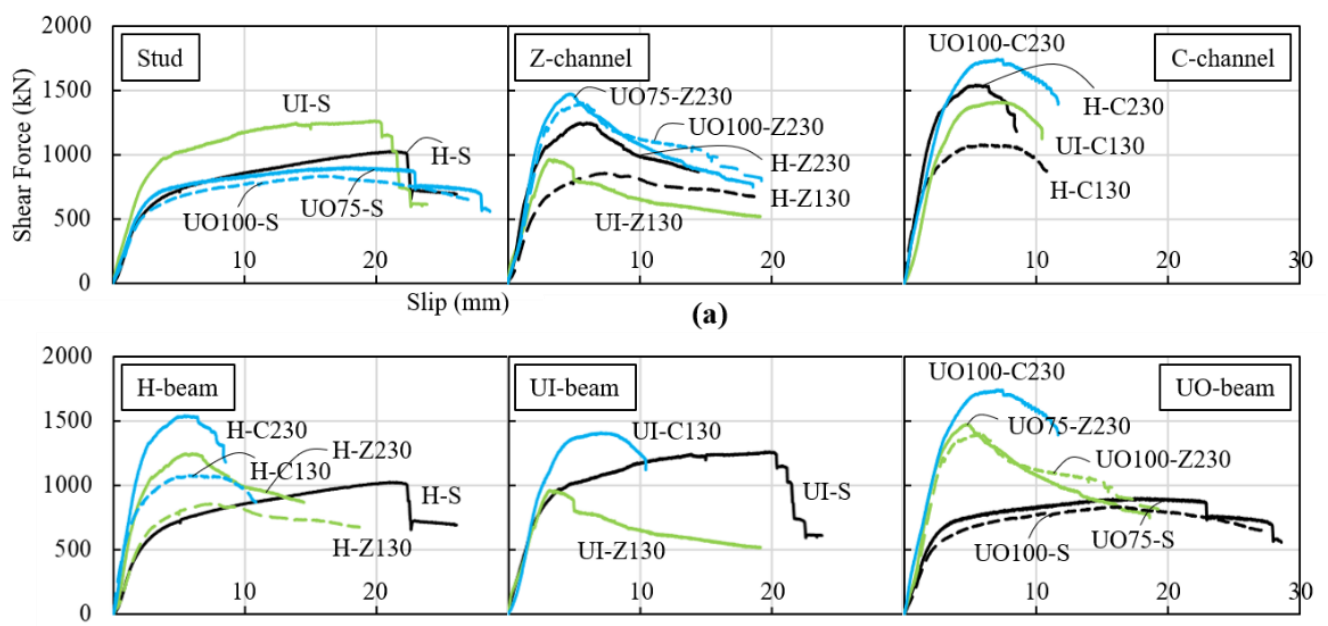

(b)

Figure 7. Comparisons of Behavior: (a) in terms of Steel Anchors; (b) in terms of Steel Beams.

\section{Discussions}

\subsection{Existing Design Equations for Stud Anchors and Fully-Welded Channel Anchors}

For the nominal shear strength $Q_{n}$ of a steel anchor (stud anchors and fully-welded channel anchors) embedded in a solid concrete slab, current design codes such as ANSI/AISC 360-16 [9] provide design equations. Table 4 summarizes existing design equations including current code equations and the other design equations available in the literature [3,9-18]. It is noted that for direct comparisons among those design equations, some of symbols were modified from the original expressions and the design factors such as strength reduction factors and partial factors were not included in the equations. 
Table 4. Existing Design Equations for Stud Anchors and Channel Anchors with Full-length Welding.

\begin{tabular}{|c|c|}
\hline Design Code or Authors & Design Equation, $Q_{n}[\mathrm{~N}]^{1}$ \\
\hline $\begin{array}{l}\text { ANSI/AISC 360-16 [9] } \\
\text { \& KDS } 413100[10]\end{array}$ & $\begin{array}{l}0.5 A_{s a} \sqrt{f^{\prime}{ }_{c} E_{c}} \leq R_{g} R_{p} A_{s a} F_{u} \text { for stud anchor } \\
\text { where } R_{g}=1.0 \text { and } R_{p}=0.75 \text { throughout the present study } \\
0.3\left(t_{f}+0.5 t_{w}\right) L_{c a} \sqrt{f^{\prime}{ }_{c} E_{c}} \text { for C-channel anchor }\end{array}$ \\
\hline CSA S16-09 [11] & $\begin{array}{l}0.5 A_{s a} \sqrt{f^{\prime}{ }_{c} E_{c}} \leq A_{s a} F_{u} \text { for stud anchor } \\
45\left(t_{f}+0.5 t_{w}\right) L_{c a} \sqrt{f^{\prime}}{ }_{c} \text { for C-channel anchor }\end{array}$ \\
\hline Yokota and Kiyomiya [12] & $\begin{array}{l}\min \left\{0.8 F_{u} A_{s a} ; 0.29 \alpha d_{s a}^{2} \sqrt{f^{\prime}{ }_{c} E_{c}}\right\} \text { for stud anchor } \\
\text { where } \alpha=0.2\left(h_{s a} / d_{s a}+1\right) \text { for } 3 \leq h_{s a} / d_{s a} \leq 4 \text { or } 1 \text { for } h_{s a} / d_{s a}>4 \\
88 \sqrt{t_{w}} L_{c a} \sqrt{f^{\prime}{ }_{c}} \text { for C-channel anchor } \\
65 \sqrt{t_{w}} L_{c a} \sqrt{f^{\prime}{ }_{c}} \text { for L-channel anchor }\end{array}$ \\
\hline Maleki and Mahoutian [13] & 27.2 $\left(t_{f}+0.5 t_{w}\right) L_{c a} \sqrt{f_{c}^{\prime}}$ for C-channel anchor \\
\hline $\begin{array}{l}\text { Pashan and Hosain [14] } \\
\text { Ros [15] }\end{array}$ & $\begin{array}{l}\left(336 t_{w}^{2}+5.24 L_{c a} h_{c a}\right) \sqrt{f_{c}^{\prime}} \text { for C-channel anchor } \\
63 \frac{t_{w w}}{h_{c a}}+1.6, \sqrt{f^{\prime}{ }_{c}} L_{c a} h_{c a} \text { for L-channel anchor }\end{array}$ \\
\hline Baran and Topkaya [3] & $0.25\left(7.2-0.023 L_{c a}\right)\left(1.5-0.005 h_{c a}\right) f^{\prime}{ }_{c} L_{c a} h_{c a}+\frac{2 t_{v}^{2} L_{c a}}{h_{c a}} F_{u}$ for C-channel anchor \\
\hline Tahmasbi et al. [16] & $\begin{array}{l}0.213 L_{c a} \sqrt{t_{w} f_{c}^{\prime}} \times 10^{3} \text { for L-channel anchor } \\
\min \left\{31 A_{s a} \sqrt{\left(h_{s a} / d_{s a}\right) f_{c}^{\prime}}+10000 ; A_{s a} F_{u}\right\} \text { for stud anchor }\end{array}$ \\
\hline JSCE [17] & $\begin{array}{l}\min \left\{0.0056 h_{c a} L_{c a} \sqrt{f_{c}^{\prime}} k_{1} k_{2} k_{3} ; 0.001 t_{s c} L_{c a} F_{u} / \sqrt{3}\right\} \text { for L-channel anchor } \\
\text { where } k_{1}=2.2\left(t_{s c} / h_{c a}\right)^{2 / 3} \leq 1.0, k_{2}=0.4 \sqrt{t_{p} / t_{s c}}+0.43 \leq 1.0 \\
k_{3}=\sqrt{s_{c a} / 10 \times h_{c a}} \leq 1.0\end{array}$ \\
\hline Qiu et al. [18] & $\begin{array}{l}k_{h} k_{2} k_{3} 195.894\left(t_{w}\right)^{0.425}\left(f^{\prime}{ }_{c}\right)^{0.383} \times L_{c a} \text { for L-channel anchor } \\
\text { where, } k_{h}=\exp \left(-1.918 t_{w} / h_{c a}\right)\end{array}$ \\
\hline
\end{tabular}

$1, d_{s a}, h_{s a}=$ cross-sectional area, diameter, and height of stud anchor; $t_{f}, t_{w}, h_{c a}, L_{c a}, s_{c a}=$ flange thickness, web thickness, height, length, and spacing of channel anchor, and $t_{s c}=$ lesser of thickness of channel anchor considering welded part and thickness of channel anchor itself; $F_{u}=$ tensile strength of steel anchor; $f^{\prime}{ }^{\prime}, E_{c}=$ compressive strength and elastic modulus of concrete; and $t_{p}=$ thickness of base steel plate (steel beam flange).

Although the design equations for channel anchors in Table 4 are for a specific shape with full-length welding, all of those equations were applied to the test specimens of the present study to verify their applicability. The elastic modulus of concrete was calculated as $E_{c}=4700 \sqrt{f^{\prime}}$ [25] in all equations for direct comparison, and the contribution $V_{n c}$ of the concrete inside the UH-beam, which was cast monolithically with concrete slabs, was taken into account in the calculation of the design shear strength $V_{n}$ as follows.

$$
\begin{gathered}
V_{n}=\Sigma Q_{n}+V_{n c} \\
V_{n c}=0.66 \times \min \left\{\sqrt{2 /\left(1+0.004 d_{c}\right)} ; 1\right\} \times\left(\rho_{w}\right)^{1 / 3} \sqrt{f^{\prime}} b_{c} d_{c} \times 2
\end{gathered}
$$

where, $V_{n c}=$ nominal shear strength provided by the concrete, which was calculated in accordance with ACI 318-19 [25] (for the case of normal-weight concrete, non-prestressed members, not providing the minimum amount of shear reinforcement, and having no axial load); $\rho_{w}=$ longitudinal reinforcement ratio; and $b_{c}, d_{c}=$ width and depth of concrete measured at the interface between the monolithically cast beam and slab $\left(b_{c}=\right.$ clear distance between top flanges of U-section, $d_{c}=$ net length excluding the width $b_{c a}$ of channel anchors). The factor of 2 in Equation (2) is for double-sided push-out testing, and the vertical reinforcement in the concrete slab (4-D13) was considered as longitudinal tension reinforcement [26] in the calculation of $\rho_{w}$.

Figure 8 shows the comparison (in this figure, each design equation is identified by an abbreviated name of the design code or authors, and $\mathrm{C}$ or $\mathrm{L}$ behind the abbreviated name indicates C- or L-channel anchor). As shown in Figure 8a, for stud anchors, the current design codes provided quite good predictions (the ratio $V_{\text {pred }} / V_{\text {test }}=V_{n} / V_{m}$ of prediction-to-test was close to 1 for all codes). On the other hand, as shown in Figure 8b,c for channel anchors, $V_{\text {pred }} / V_{\text {test }}$ was scattered widely, but unexpectedly, each equation 
showed a similar tendency for both fully-welded channel anchors and partially-welded channel anchors. Among the predictions, the combination of the equation of Maleki and Mahoutian [13] and Equations (1) and (2) best matched with the test results (mean and standard deviation of $V_{\text {pred }} / V_{\text {test }}$ was $m \pm \sigma=0.80 \pm 0.13$ for fully-welded channel anchors or $0.77 \pm 0.15$ for partially-welded channel anchors). It is noted that the overall average of the calculated concrete contribution $V_{n c}$ by Equation (2) was $6.6 \%$ of $V_{n} \cdot\left(V_{n c} / V_{n}\right.$ was in the range of $3.0-12.1 \%$ for all cases).

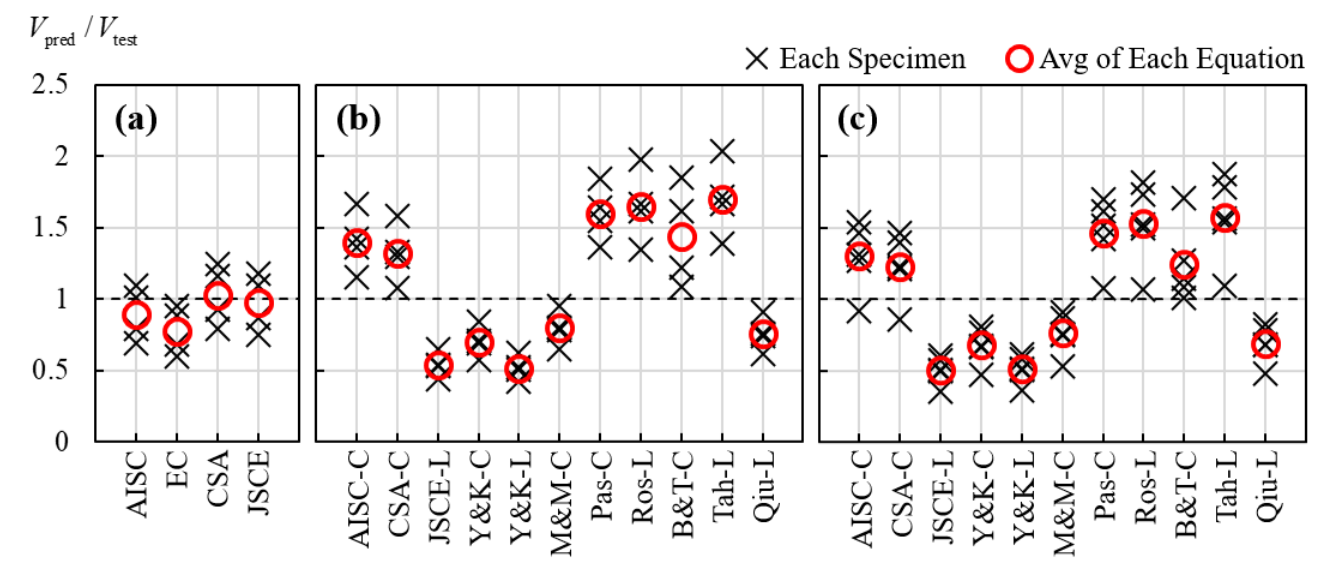

Figure 8. Comparison of Predictions to Tests: (a) Stud Anchors; (b) Fully-welded Channel Anchors (H-beams); (c) Partially-welded Channel Anchors (UH-beams).

Although some of the equations showed relatively good and conservative predictions suitable for design purpose, this is limited only to the test results of the present study. Fundamentally, it is not appropriate to apply the existing design equations for fully-welded channel anchors to the design of partially-welded channel anchors, because the failure mode and shear strength are strongly affected by the shape and welding condition of steel anchors $[4,5,12]$.

\subsection{Comparison to Existing Design Equations for Channel Anchors with Partial-Length Welding}

As mentioned above, it is not suitable to apply the existing design equations for fully-welded channel anchors to the design of partially-welded channel anchors. For this reason, as given in Equation (3), AC495 [27] provides the design equation for L-channel anchors welded to U-shaped cold-formed steel beams, which is similar to the equation of ANSI-AISC 360-16 [9].

$$
Q_{n}=\frac{0.6 \times 100^{3 / 2}\left(t_{f}+0.5 t_{w}\right) \sqrt{f^{\prime}{ }_{c} E_{c}}}{\sqrt{L_{b w}}}
$$

where, $L_{b w}=$ web-to-web clear distance of the U-shaped cold-formed steel beam.

Meanwhile, Keo et al. [4] also proposed a design equation for inversed L-channel anchors with partial-length welding based on their push-out tests and parametric study of finite element simulations.

$$
Q_{n}=2\left(A_{c a 1}+A_{c a 2}\right) \frac{F_{u}}{\sqrt{3}}+2\left(19-38.1 \frac{b_{c a}}{d_{\text {slab }}}\right) A_{c b} f_{c}^{\prime}
$$

where, $A_{c a 1}, A_{c a 2}, A_{c b}=$ shear plane areas, and bearing area of channel anchors, respectively. Those definitions are illustrated in the literature [4], but approximately $A_{c a 1}=t_{w} L_{c a, w}$, $A_{c a 2}=t_{f} b_{c a}$, and $A_{c b}=t_{f} L_{c a, w}$ were used in the present study. $b_{c a}=$ width of channel anchor; $L_{c a, w}=$ welded length of channel anchor measured at one end; and $d_{\text {slab }}=$ depth of concrete slab. 
Those two equations were applied to the test results for comparison. It is noted that unlike the design equations in Table 4, in Equations (3) and (4), the contribution $V_{n c}$ of concrete was taken into account implicitly. Thus, the design shear strength was calculated as $V_{n}=\Sigma Q_{n}$. To compare over a wider range of design parameters such as the type of steel anchors, the other test results available in the literatures [4-6] were also included. Some of information that was not clearly specified in the literature was assumed based on the figures in the literature, and the test parameters are summarized in Appendix A.

Figure 9 and Table 5 show the comparison. In overall, the equation of Keo et al. [4] ( $m \pm \sigma$ of $V_{\text {pred }} / V_{\text {test }}=0.94 \pm 0.28$ ) gave the better prediction on average, but it scattered wider compared to the equation of AC495 [27] (1.32 \pm 0.23$)$ : to be more specific, $1.07 \pm 0.11$ for C-channel anchors, $1.42 \pm 0.09$ for L-channel anchors, $1.34 \pm 0.24$ for inversed L-channel anchors, and $1.19 \pm 0.24$ for Z-channel anchors in the case of the equation of AC495 [27], while $0.87 \pm 0.02$ for $C$-channel anchors, $0.52 \pm 0.04$ for L-channel anchors, $1.01 \pm 0.26$ for inversed L-channel anchors, and $1.06 \pm 0.14$ for Z-channel anchors in the case of the equation of Keo et al. [4]. The equation of Keo et al. [4] was derived for inversed L-channel anchors having no top flange, but it showed relatively good agreement for all anchor shapes because the uplift of concrete slabs was prevented by hoop reinforcement in their study.

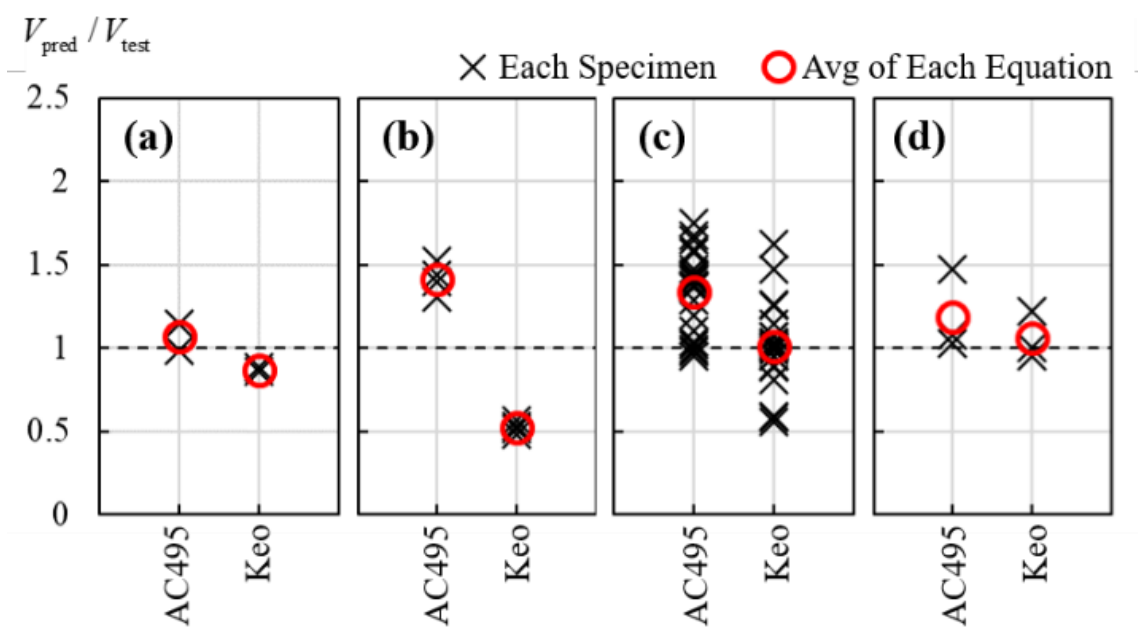

Figure 9. Comparison of Predictions to Tests: (a) C-channel Anchors; (b) L-channel Anchors; (c) Inversed L-channel Anchors; (d) Z-channel Anchors.

Although the number of samples used in the comparison was limited, both equations were considered applicable to design, considering the fact that the design factors such as strength reduction factors and partial factors are used in actual design. For safer and more economic design, further experimental studies with various parameters are required. 
Table 5. Comparison of Test Results with Predictions by Existing Design Equations for Channel Anchor with Partial-length Welding (units in $\mathrm{kN}$ ).

\begin{tabular}{|c|c|c|c|c|c|}
\hline Authors & Specimen & Anchor Shape & $V_{\text {test }}$ & $\begin{array}{c}V_{\text {pred }} \\
\text { by Equation (3) }\end{array}$ & $\begin{array}{c}V_{\text {pred }} \\
\text { by Equation (4) }\end{array}$ \\
\hline \multirow[t]{5}{*}{ Present Study } & UI-Z130 & Z & 963.5 & 1071.6 & 1178.3 \\
\hline & UO75-Z230 & Z & 1473.3 & 1117.6 & 1407.5 \\
\hline & UO100-Z230 & $\mathrm{Z}$ & 1401.2 & 1117.6 & 1407.5 \\
\hline & UI-C130 & $\mathrm{C}$ & 1409.8 & 1229.6 & 1250.2 \\
\hline & UO100-C230 & $\mathrm{C}$ & 1740.9 & 1281.5 & 1493.4 \\
\hline \multirow[t]{4}{*}{ Keo et al. [4] } & PO-L40 & Inv-L & 637.1 & 604.6 & 516.3 \\
\hline & PO-L50a & Inv-L & 932.1 & 924.2 & 521.0 \\
\hline & PO-L50b & Inv-L & 916.5 & 935.8 & 540.5 \\
\hline & PO-L50c & Inv-L & 975.9 & 951.9 & 567.3 \\
\hline \multirow[t]{18}{*}{ Kim et al. [5] } & EA-30-20-200 & Inv-L & 404.0 & 447.4 & 463.7 \\
\hline & EA-30-30-200 & Inv-L & 488.0 & 583.5 & 463.7 \\
\hline & EA-30-40-200 & Inv-L & 488.0 & 719.7 & 463.7 \\
\hline & EA-30-20-300 & Inv-L & 324.0 & 335.5 & 347.7 \\
\hline & EA-30-30-300 & Inv-L & 339.0 & 437.6 & 347.7 \\
\hline & EA-30-40-300 & Inv-L & 390.0 & 539.8 & 347.7 \\
\hline & EA-40-20-200 & Inv-L & 476.0 & 833.4 & 772.8 \\
\hline & EA-40-30-200 & Inv-L & 720.0 & 1039.5 & 772.8 \\
\hline & EA-40-40-200 & Inv-L & 744.0 & 1245.6 & 772.8 \\
\hline & EA-40-20-300 & Inv-L & 393.0 & 625.1 & 579.6 \\
\hline & EA-40-30-300 & Inv-L & 573.0 & 779.6 & 579.6 \\
\hline & EA-40-40-300 & Inv-L & 567.0 & 934.2 & 579.6 \\
\hline & EA-50-20-200 & Inv-L & 732.0 & 1053.1 & 927.3 \\
\hline & EA-50-30-200 & Inv-L & 924.0 & 1265.1 & 927.3 \\
\hline & EA-50-40-200 & Inv-L & 940.0 & 1477.1 & 927.3 \\
\hline & EA-50-20-300 & Inv-L & 555.0 & 789.8 & 695.5 \\
\hline & EA-50-30-300 & Inv-L & 693.0 & 948.8 & 695.5 \\
\hline & EA-50-40-300 & Inv-L & 789.0 & 1107.8 & 695.5 \\
\hline \multirow[t]{5}{*}{ Lee et al. [6] } & AN-160-60-4.5 & $\mathrm{L}$ & 1561.6 & 2185.5 & 800.1 \\
\hline & AN-160-60-6 & $\mathrm{L}$ & 1877.5 & 2866.1 & 1066.8 \\
\hline & AN-160-80-4.5 & $\mathrm{L}$ & 1670.6 & 2185.5 & 800.1 \\
\hline & AN-160-80-6 & $\mathrm{L}$ & 1996.4 & 2866.1 & 1066.8 \\
\hline & \multicolumn{3}{|c|}{ Accuracy of Prediction: $m \pm \sigma$ of $V_{\text {pred }} / V_{\text {test }}$} & $1.32 \pm 0.23$ & $0.94 \pm 0.28$ \\
\hline
\end{tabular}

\section{Conclusions}

To investigate the behavior of various steel anchors, push-out tests were performed on the test parameters including the geometry of steel beams (H-beams and UH-beams) and the type of steel anchors (stud anchors, and Z- and C-channel anchors with full- or partial-length welding), and the test results were compared with predictions by various design equations for steel anchors available in the literature. The research findings are summarized as follows.

(1) Although channel anchors with partial-length welding are widely used in current composite construction, the majority of current design codes and previous studies are for channel anchors with full-length welding.

(2) Push-out test results showed that the performance of test specimens strongly depends on the types of steel anchors rather than the geometry of steel beams. The specimens with C-channel anchors showed highest load-carrying capacity but most drastic load reduction after the peak load. The specimens with Z-channel anchors showed a similar behavior to those with C-channel anchors, but the load reduction occurred in a slightly slower rate. The load-carrying capacity was increased with the length of Zand C-channel anchors. The specimens with stud anchors reached the peak load in a slow rate and showed most ductile behavior.

(3) Some of existing design equations for fully-welded channel anchors showed relatively good and conservative predictions after considering the contribution of the concrete 
inside the UH-beam cast monolithically with concrete slabs, but, fundamentally, it is not appropriate to apply the existing design equations for fully-welded channel anchors to the design of partially-welded channel anchors, because the failure mode and shear strength are strongly affected by the shape and welding condition of steel anchors.

(4) Existing two design equations for partially-welded channel anchors were compared with the present and previous test results. The comparison showed that both equations are considered applicable to design, considering the fact that the design factors such as strength reduction factors and partial factors are used in actual design.

It is noted that the verification of the existing design equations was made only for limited number of samples. For safer and more economic design, further experimental studies with various design parameters are required, especially for beam specimens which are more realistic in practice.

Author Contributions: Conceptualization, I.-R.C.; methodology, I.-R.C.; validation, I.-R.C.; formal analysis, C.-S.K.; investigation, I.-R.C.; resources, I.-R.C. and C.-S.K.; data curation, I.-R.C. and C.-S.K.; writing-original draft preparation, I.-R.C. and C.-S.K.; writing-review and editing, I.-R.C. and C.-S.K.; visualization, I.-R.C. and C.-S.K.; supervision, I.-R.C.; project administration, I.-R.C.; funding acquisition, I.-R.C. and C.-S.K. Both authors have read and agreed to the published version of the manuscript.

Funding: This research and the APC was partly supported by Technology development Program (S2543848) funded by the Ministry of SMEs and Startups (MSS, Korea) and the National Research Foundation of Korea (NRF) grant funded by the Korea government (MSIT) (No. 2019R1C1C1010052), and the authors are grateful for their supports.

Conflicts of Interest: The authors declare no conflict of interest.

\section{Notations}

$A_{c a 1}$ shear plane area 1 of channel anchor

$A_{c a 2}$ shear plane area 2 of channel anchor

$A_{c b} \quad$ bearing area of channel anchor

$A_{s a} \quad$ cross-sectional area of stud anchor

$b_{c} \quad$ width of concrete measured at the interface between monolithically cast beam and slab

$b_{c a} \quad$ width of channel anchor

$d_{c} \quad$ depth of concrete measured at the interface between monolithically cast beam and slab

$d_{s a} \quad$ shank diameter of stud anchor

$d_{\text {slab }}$ depth of concrete slab

$E_{c} \quad$ elastic modulus of concrete

$f_{\mathcal{C}} \quad$ compressive strength of concrete

$F_{u} \quad$ tensile strength of steel

$F_{y} \quad$ yield strength of steel

$h_{c a}$ height of channel anchor

$h_{s a} \quad$ height of stud anchor

$K_{i} \quad$ initial stiffness or secant stiffness at the point where steel anchors reach yield strain

$L_{b w} \quad$ web-to-web clear distance of U-shaped cold-formed steel beam

$L_{c a} \quad$ length of channel anchor

$L_{c a, w}$ welded length of channel anchor measured at one end

$Q_{n} \quad$ nominal shear strength of a steel anchor

$s_{c a} \quad$ spacing of channel anchor

$t_{f} \quad$ flange thickness of channel anchor

$t_{p}$ thickness of plate 


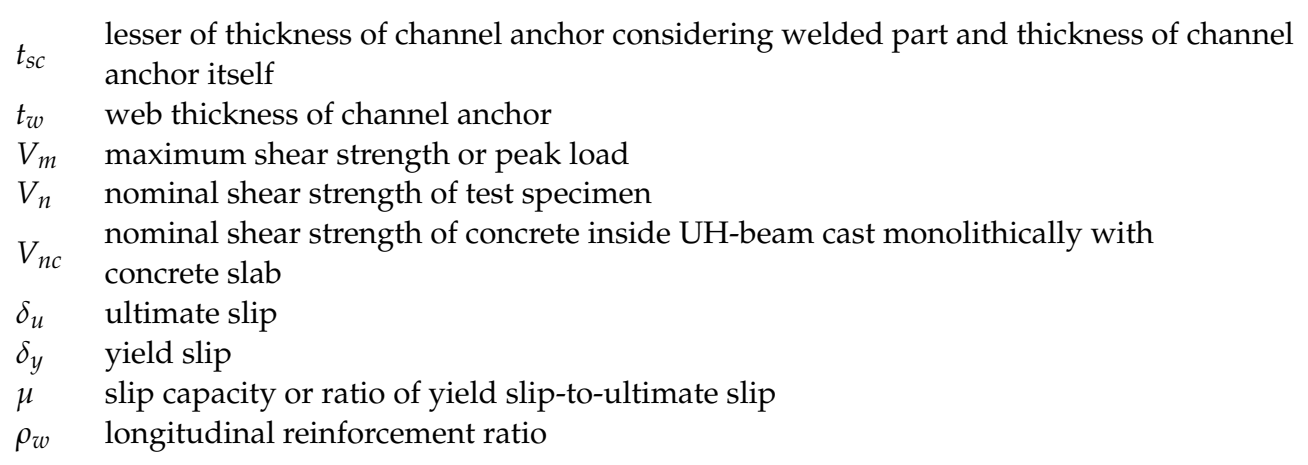

\section{Appendix A}

Table A1. Test Parameters of Previous Studies for Channel Anchor with Partial-length Welding (units in $\mathrm{mm}, \mathrm{MPa}$ ).

\begin{tabular}{|c|c|c|c|c|}
\hline Authors & Specimen & $\begin{array}{c}\text { Channel Anchor } \\
h_{s a} \times b_{s a} \times t_{w} \times t_{f}, F_{u}, L_{s a, w}\end{array}$ & $\begin{array}{l}\text { Concrete } \\
\text { Slab } \\
f_{c^{\prime}} d_{\text {slab }}\end{array}$ & $\begin{array}{l}\text { Steel Beam } \\
L_{b w}\end{array}$ \\
\hline \multirow[t]{4}{*}{ Keo et al. [4] } & PO-L40 & Inv-L40 $\times 40 \times 4 \times 4,550,20$ & $27.0,200$ & 288 \\
\hline & PO-L50a & Inv-L50 × $50 \times 5 \times 5,445,40$ & $20.3,200$ & 288 \\
\hline & PO-L50b & Inv-L50 × $50 \times 5 \times 5,445,40$ & $21.3,200$ & 288 \\
\hline & PO-L50c & Inv-L50 × $50 \times 5 \times 5,445,40$ & $22.7,200$ & 288 \\
\hline \multirow[t]{18}{*}{ Kim et al. [5] } & EA-30-20-200 & Inv-L30 × $30 \times 3 \times 3,421,20$ & $28.5,150$ & 388 \\
\hline & EA-30-30-200 & Inv-L30 × $30 \times 3 \times 3,421,30$ & $28.5,150$ & 388 \\
\hline & EA-30-40-200 & Inv-L30 × $30 \times 3 \times 3,421,40$ & $28.5,150$ & 388 \\
\hline & EA-30-20-300 & Inv-L30 × $30 \times 3 \times 3,421,20$ & $28.5,150$ & 388 \\
\hline & EA-30-30-300 & Inv-L30 × $30 \times 3 \times 3,421,30$ & $28.5,150$ & 388 \\
\hline & EA-30-40-300 & Inv-L30 × $30 \times 3 \times 3,421,40$ & $28.5,150$ & 388 \\
\hline & EA-40-20-200 & Inv-L40 × $40 \times 5 \times 5,456,20$ & $28.5,150$ & 388 \\
\hline & EA-40-30-200 & Inv-L40 × $40 \times 5 \times 5,456,30$ & $28.5,150$ & 388 \\
\hline & EA-40-40-200 & Inv-L40 $\times 40 \times 5 \times 5,456,40$ & $28.5,150$ & 388 \\
\hline & EA-40-20-300 & Inv-L40 × $40 \times 5 \times 5,456,20$ & $28.5,150$ & 388 \\
\hline & EA-40-30-300 & Inv-L40 × $40 \times 5 \times 5,456,30$ & $28.5,150$ & 388 \\
\hline & EA-40-40-300 & Inv-L40 × $40 \times 5 \times 5,456,40$ & $28.5,150$ & 388 \\
\hline & EA-50-20-200 & Inv-L50 × $50 \times 6 \times 6,454,20$ & $28.5,150$ & 388 \\
\hline & EA-50-30-200 & Inv-L50 × $50 \times 6 \times 6,454,30$ & $28.5,150$ & 388 \\
\hline & EA-50-40-200 & Inv-L50 × $50 \times 6 \times 6,454,40$ & $28.5,150$ & 388 \\
\hline & EA-50-20-300 & Inv-L50 × $50 \times 6 \times 6,454,20$ & $28.5,150$ & 388 \\
\hline & EA-50-30-300 & Inv-L50 × $50 \times 6 \times 6,454,30$ & $28.5,150$ & 388 \\
\hline & EA-50-40-300 & Inv-L50 × $50 \times 6 \times 6,454,40$ & $28.5,150$ & 388 \\
\hline \multirow[t]{4}{*}{ Lee et al. [6] } & AN-160-60-4.5 & $\mathrm{L} 60 \times 40 \times 4.5 \times 4.5,493,80$ & $29.2,200$ & 304 \\
\hline & AN-160-60-6 & $\mathrm{L} 60 \times 40 \times 6 \times 6,478,80$ & $29.2,200$ & 304 \\
\hline & AN-160-80-4.5 & $\mathrm{L} 80 \times 40 \times 4.5 \times 4.5,493,80$ & $29.2,200$ & 304 \\
\hline & AN-160-80-6 & $\mathrm{L} 80 \times 40 \times 6 \times 6,478,80$ & $29.2,200$ & 304 \\
\hline
\end{tabular}

\section{References}

1. Johnson, R.P. Composite Structures of Steel and Concrete-Beams, Slabs, Columns, and Frames for Buildings, 3rd ed.; Blackwell Publishing: Oxford, UK, 2004; pp. 1-230.

2. Kim, C.-S.; Park, H.-G.; Chung, K.-S.; Choi, I.-R. Eccentric Axial Load Testing for Concrete-Encased Steel Columns Using $800 \mathrm{MPa}$ Steel and $100 \mathrm{MPa}$ Concrete. J. Struct. Eng. 2012, 138, 1019-1031. [CrossRef]

3. Baran, E.; Topkaya, C. An experimental study on channel type shear connectors. J. Constr. Steel Res. 2012, 74, 108-117. [CrossRef]

4. Keo, P.; Lepourry, C.; Somja, H.; Palas, F. Behavior of a new shear connector for U-shaped steel-concrete hybrid beams. J. Constr. Steel Res. 2018, 145, 153-166. [CrossRef]

5. Kim, Y.J.; Bae, J.H.; Ahn, T.S.; Jang, D.W. Push-out Test on Welded Angle Shear Connectors used in Composite Beams. J. Korean Soc. Steel Constr. 2014, 26, 155. [CrossRef]

6. $\quad$ Lee, M.-K.; Shin, K.-J.; Lee, J.-S.; Chae, I.-S. Push-out Test on Evaluation of Shear Strength Using Angle Shear Connectors. J. Korean Soc. Steel Constr. 2019, 31, 413-421. [CrossRef] 
7. Viest, I.M.; Siess, C.P.; Appleton, J.H.; Newmark, N. Full-Scale Tests of Channel Shear Connectors and Composite T-beams; University of Illinois Bulletin: Urbana, IL, USA, 1952; Volume 50, pp. 1-155.

8. Slutter, R.G.; Driscoll, G.C. Flexural strength of steel-concrete composite beams. J. Struct. Div. ASCE 1965, 91, 71-99.

9. AISC. Specification for Structural Steel Buildings (ANSI/AISC 360-16); American Institute of Steel Construction: Chicago, IL, USA, 2016.

10. Korea Construction Standards Center. Design Standards for Structural Steel Buildings (KDS 4131 00); Korea Construction Standards Center: Goyang-si, Korea, 2019.

11. CSA. Design of Steel Structures (CSA S16-09); Canadian Standards Association: Mississauga, ON, Canada, 2009.

12. Yokota, H.; Kiyomiya, O. Load carrying capacity of shear connectors made of shaped steel in steel-concrete composite members. In Technical Note of The Port and Harbour Research Institute (No.595); Ministry of Transport: Tokyo, Japan, 1987.

13. Maleki, S.; Mahoutian, M. Experimental and analytical study on channel shear connectors in fiber-reinforced concrete. J. Constr. Steel Res. 2009, 65, 1787-1793. [CrossRef]

14. Pashan, A.; Hosain, M.U. New design equations for channel shear connectors in composite beams. Can. J. Civ. Eng. 2009, 36, 1435-1443. [CrossRef]

15. Soty, R.; Shima, H. Formulation for Shear Force-Relative Displacement Relationship of L-Shape Shear Connector in Steel-Concrete Composite Structures. Ph.D. Thesis, Kochi University of Technology, Kochi, Japan, 2011.

16. Tahmasbi, F.; Maleki, S.; Shariati, M.; Sulong, N.H.R.; Tahir, M.M. Shear Capacity of C-Shaped and L-Shaped Angle Shear Connectors. PLoS ONE 2016, 11, e0156989. [CrossRef] [PubMed]

17. JSCE Committee on Hybrid Structures. Standard Specifications for Hybrid Structures (JSCE); Japan Society of Civil Engineers: Tokyo, Japan, 2014.

18. Qiu, S.-Y.; Guo, Y.-T.; Nie, X.; Fan, J.-S.; Tao, M.-X. Experimental study on shaped steel shear connectors used in large-scale composite structures. J. Constr. Steel Res. 2020, 172, 106201. [CrossRef]

19. CEN. Eurocode 4: Design of Composite Steel and Concrete Structures_Part 1.1: General Rules and Rules for Buildings (Eurocode 4-04); European Committee for Standardization: Brussels, Belgium, 2004.

20. Korea Industrial Standards Commission. Steel Bars for Concrete Reinforcement (KS D 3504); Korea Industrial Standards: Seoul, Korea, 2019.

21. Korea Industrial Standards Commission. Headed Studs (KS B 1062); Korea Industrial Standards: Seoul, Korea, 2014.

22. Korea Industrial Standards Commission. Method of Tensile Test for Metallic Materials (KS B 0802); Korea Industrial Standards: Seoul, Korea, 2018.

23. Korea Industrial Standards Commission. Standard Test Method for Compressive Strength of Concrete (KS F 2405); Korea Industrial Standards: Seoul, Korea, 2017.

24. Park, R. Evaluation of ductility of structures and structural assemblages from laboratory testing. Bull. N. Z. Natl. Soc. Earthq. Eng. 1989, 22, 155-166. [CrossRef]

25. ACI Committee 318. Building Code Requirements for Structural Concrete and Commentary (ACI 318-19); American Concrete Institute: Farmington Hills, MI, USA, 2019.

26. Kuchma, D.A.; Wei, S.; Sanders, D.H.; Belarbi, A.; Novak, L.C. The development of the one-way shear design provisions of ACI 318-19. ACI Struct. J. 2019, 116, 285-295.

27. ICC-ES. AC495-Cold-Formed Steel Structural Beams with Steel Angle Anchors Acting Compositely with Cast-in-Place Concrete Slabs; ICC Evaluation Service, LLC.: Brea, CA, USA, 2018. 